hence to low concentrations of IGF I and the main binding protein. ${ }^{8}$ Although some binding proteins that are not dependent on growth hormone exist, reduction of the major binding protein might lead to an increased amount of unbound, biologically active free peptide for any given plasma concentration. ${ }^{9}$

Our patient had hypoinsulinaemic hypoglycaemia and noticeably suppressed growth hormone and IGF I concentrations but with a concentration of IGF II that was, inappropriately, near the upper end of the normal range. The ratio of IGF I to IGF II, which is normally fairly constant, ${ }^{5}$ was grossly abnormal. Postoperatively the concentration of all these peptide hormones returned to within the normal reference ranges, including the IGF I : IGF II ratio. These data imply that autonomous secretion of IGF II by the subpleural fibroma was responsible for the presenting symptom of spontaneous hypoglycaemia. Although these tumours may be very large at presentation, radical surgical excision is usually possible and is the preferred treatment. Tumour recurrence is almost invariably local, and in a few cases has led to the recurrence of spontaneous hypoglycaemia. ${ }^{10}$

This case gives weight to the view that some cases of tumour associated hypoglycaemia are due to secretion by the tumour of peptides that have both insulin like and growth factor activity.

1 Doege KW. Fibrosarcoma of the mediastinum. Ann Surg 1930;92:955-61.

2 Briselli M, Mark EJ, Dickerson GR. Solitary fibrous tumors of the pleura. Eight new cases and review of 360 cases in the literature. Cancer 1981;47:2678-89.

3 Gorden P, Hendricks CM, Kahn CR, Megyesi K, Roth J. Hypoglycemia associated with non-islet-cell tumour and insulin-like growth factors. $N$ Engl J Med 1981;305: 1452-5.

4 Herbert A. Pathogenesis of pleurisy, pleural fibrosis, and mesothelial proliferation. Thorax 1986;41:176-89.

5 Teale JD, Marks V. Inappropriately elevated plasma insulin-like growth factor II in relation to suppressed insulin-like growth factor I in the diagnosis of non-islet cell tumour hypoglycaemia. Clin Endocrinol (Oxf) 1990; 33:87-98.

6 Zapf J, Walter H, Froesch ER. Radioimmunological determination of insulin-like growth factors I and II in normal subjects and in patients with growth disorders and extrapancreatic tumor hypoglycemia. J Clin Invest 1981; 68:1321-30.

7 Daughaday WH, Emanuele MA, Brooks MN, Balbato AL, Kapadia M, Rotwein P. Synthesis and secretion of insulin-like growth factor II by a leiomyosarcoma with associated hypoglycemia. $N$ Engl $J$ Med 1988;319: 1434-40.

8 Ron D, Powers AC, Pandian MR, Godine JE, Axelrod L. Increased insulin-like growth factor II production and consequent suppression of growth hormone secretion: a dual mechanism for tumor induced hypoglycemia. J Clin Endocrinol Metab 1989;68:701-6.

9 Merimee T. Insulin-like growth factors in patients with nonislet cell tumors and hypoglycemia. Metabolism 1986;35:360-3.

10 Okike N, Bernatz PE, Woolner LB. Localised mesothelioma of the pleura. J Thorac Cardiovasc Surg 1978;75:363-72.

\section{Endoscopic bougie and balloon dilatation of multiple bronchial stenoses: 10 year follow up}

\author{
J B Ball, J C Delaney, C C Evans, \\ R J Donnelly, C R K Hind
}

\begin{abstract}
This paper reports 10 year follow up data on four patients who underwent mechanical dilatation of multiple bronchial stenoses (sarcoidosis two cases, berylliosis one case, idiopathic stenoses one case). Two patients enjoyed symptomatic and physiological improvement during the nine years before they presented with a recurrence of stenosis. The other two had recurrences sooner, and improved only slightly after they had started prednisolone treatment.
\end{abstract}

In 1981 the Liverpool Cardiothoracic Centre reported four cases in which bougie dilatation at rigid bronchoscopy was used successfully to treat multiple bronchial stenoses. ${ }^{1}$ Ten years later we have reviewed the outcome. Two of the patients have biopsy proved sarcoidosis, one idiopathic bronchostenoses, and one berylliosis.

\section{Case reports}

CASE 1

A 51 year old man was diagnosed as having pulmonary sarcoidosis in 1971 by endobronchial biopsy. During 1973-8 he developed progressive exertional dyspnoea and had recurrent chest infections. He presented in 1979 with breathlessness on mild exertion, stridor, fixed wheeze in the left midzone, and reduced breath sounds at both apices. The flow-volume loop suggested central airway obstruction and tomography showed bilateral bronchial stenoses.

Fibreoptic bronchoscopy showed multiple fibrotic stenoses with pale, non-erythematous mucosa. The segmental bronchi of the right upper lobe were narrowed to $0.5-2.0 \mathrm{~mm}$ and the right middle lobe bronchus to $3.0 \mathrm{~mm}$. In the left lung the diameters of the orifices of the upper lobe, lingula, and lower lobe bronchi
Arrowe Park Hospital, J C Delaney

Reprint requests to: Dr Hind

Accepted 11 June 1990

Cardiothoracic
Centre, Liverpool
L14 3PE
J B Ball
C C Evans
R J Donnelly
C R K Hind
Arrowe Park Hospital,
Wirral L49 5PE
J C Delaney
Reprint requests to:
Dr Hind
Accepted 11 June 1990


Results of serial pulmonary function tests in four patients with multiple bronchial stenoses before and after endoscopic dilatation

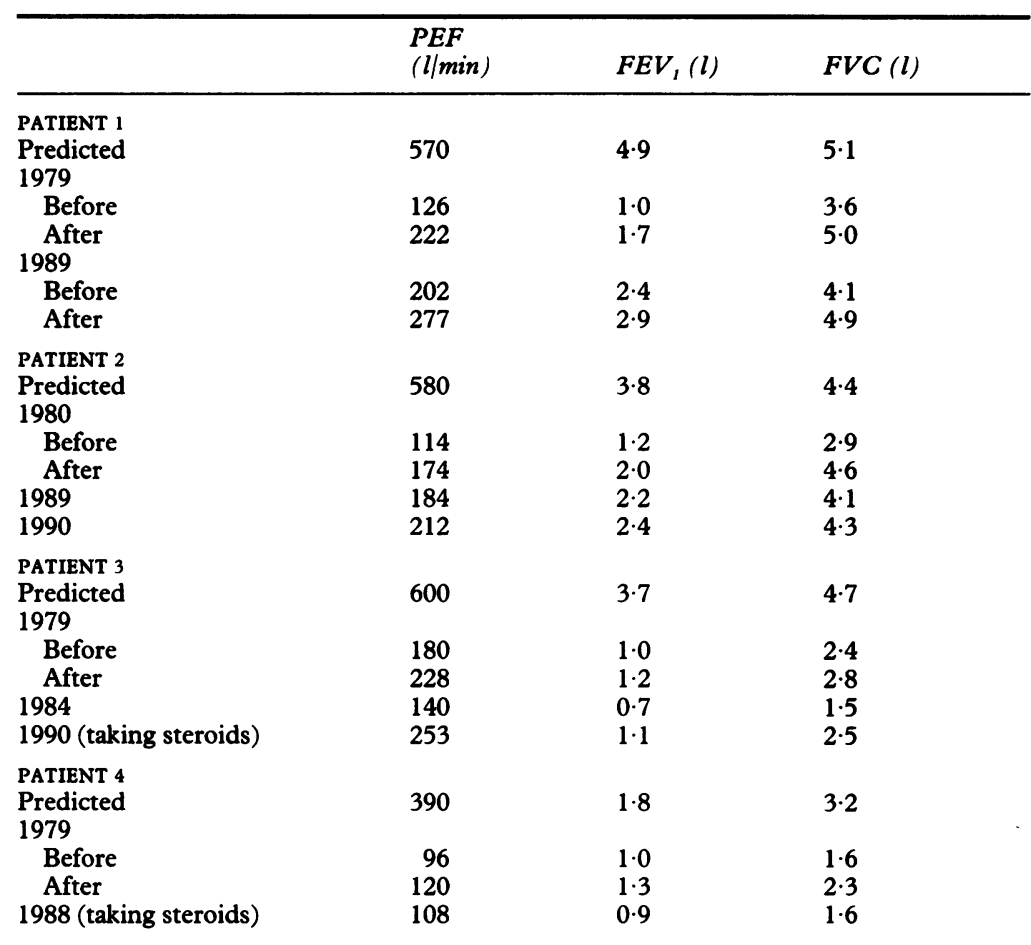

PEF-peak expiratory flow; $\mathrm{FEV}_{1}$-forced expiratory volume in one second; FVC—forced vital capacity. ing to 6.0 and $2.0 \mathrm{~mm}$. The bronchus intermedius was narrowed to $3.0 \mathrm{~mm}$. The stenosed bronchi appeared pale and fibrous and were dilated to $9.0 \mathrm{~mm}$ with bougies.

Symptomatic and spirometric improvement was observed (table) and he remained well for nine years, working and playing football until 1989, when his stridor returned. Bronchoscopy then showed that the main bronchi remained dilated, but that there was considerable narrowing of the smaller segmental bronchi in both lungs, which were inaccessible to bougies. Six months later his condition is stable. The aetiology of his bronchostenoses remains unknown.

\section{CASE 3}

A 53 year old man was diagnosed as having berylliosis in 1971. He presented in 1979 with a five year history of progressive breathlessness and wheeze complicated by frequent chest infections. Serial chest radiographs showed gradual shrinkage of the right upper lobe. He was dyspnoeic on moderate exertion and had wheeze in the right upper lobe. The results of pulmonary function tests were consistent with airflow obstruction and the flow-volume loop showed a steeple collapse suggesting emphysema. At bronchoscopy the right upper lobe segmental bronchi were stenosed to $2.0 \mathrm{~mm}$, the right middle lobe bronchus was reduced to a slit, and the bronchial mucosa was reddened and oedematous. The left lobar bronchi were normal. The right middle lobe bronchus was dilated to $8.0 \mathrm{~mm}$ with bougies but the right upper lobe was inaccessible.

Although spirometric improvement was only slight, the relief of symptoms was considerable and was maintained over the next five years. At review in 1984 he complained of increasing breathlessness, which was reflected in his pulmonary function values (table). Bronchoscopy showed oedematous restenosis in the same distribution. The right upper lobe and right middle lobe bronchi were occluded and dilatation was not possible. Systemic corticosteroid treatment was started and has resulted in some symptomatic improvement. Over the past five years there has been little clinical, spirometric, or radiographic change. The bronchoscopic appearances in 1990 were identical to those in 1984 and attempted dilatation, this time with balloon catheters, was unsuccessful. Inhaled bronchodilators have added to the clinical benefit obtained from corticosteroids.

\section{CASE 4}

A 43 year old woman was diagnosed as having endobronchial sarcoidosis by bronchial biopsy in 1976 . She was referred in 1979 after systemic corticosteroids had failed to improve her stridor, exertional dyspnoea, and recurrent bronchitis. Examination disclosed bilateral basal expiratory wheeze, a fixed wheeze in the left midzone anteriorly, and diminished breath sounds at the left apex. The flow-volume loop suggested major airway narrowing and left main bronchial stenosis was confirmed on tomography. At bronchoscopy the bronchial The flow-volume loop was characteristic of major airway narrowing and tomography showed bilateral bronchial stenoses. No cause for these stenoses was evident. Bronchoscopy showed right and left main bronchial narrow- 
mucosa was noted to be granular, erythematous, and oedematous. The left main bronchus was curved and narrowed, the left upper lobe orifice reduced to a pin-hole, and the left lower lobe and right upper lobe bronchi stenosed to $4.0 \mathrm{~mm}$. The left main bronchus was dilated with bougies and the left lower lobe bronchus was dilated blindly with an Eder Puestow dilator over a guide wire.

Clinical and spirometric improvement was substantial (table) but shortlived and over the next three years bougie dilatation was repeated on 11 occasions. Each time there was moderate symptomatic improvement, but it was noted that the bronchial mucosa was strikingly inflamed; so in 1982 oral prednisolone treatment was reintroduced. Since then her condition has remained fairly stable. She is dyspnoeic on mild exertion and has been unable to work for the past three years. Recurrent chest infections remain a problem though she is able to control her symptoms by a combination of antibiotics and courses of high dose prednisolone.

\section{Discussion}

Acquired bronchial stenosis is well recognised complication of several disease processes, including tuberculosis, ${ }^{2}$ sarcoidosis, ${ }^{3}$ Wegener's granulomatosis, ${ }^{4}$ carcinoma, and inhalational trauma, ${ }^{5}$ in addition to its occurrence as a postoperative complication (for example, sleeve resection of bronchial carcinoma and single lung transplanation). ${ }^{56}$ Established treatments include surgical resection, ${ }^{7}$ cryotherapy, ${ }^{8}$ laser photocoagulation, ${ }^{9}$ insertion of plastic or self expandable stents, ${ }^{10}$ and mechanical dilatation using either bougies or balloon catheters. ${ }^{15}$ Of these modalities the last two have been adopted relatively recently. Short term follow up over periods of 12-18 months showed encouraging results with little evidence of restenosis. ${ }^{1}$ However, this paper is, to our knowledge, the first report of long term follow up of such cases.

The initial results from these four patients, reported in 1981, confirmed that successful dilatation produces immediate clinial and spirometric improvement. ${ }^{1}$ This follow up study, however, shows that the initial improvement was not a good predictor of the long term outcome. Whether the initial endobronchial appearances predict a long term response cannot be determined from only four cases. Certainly the two cases of stenosed bronchi having a reddened, oedematous appearance (suggesting an active inflammatory process)-for example, case 1-responded badly, whereas those with a pale, fibrous appearance (suggesting a completed or "burned out" inflammatory process)-for example, case 4-responded well, and these patients have enjoyed long term improvement. Both patients with the bronchial appearance of active inflammation required systemic corticosteroids to maintain the clinical improvement initially achieved by mechanical dilatation.

These results suggest that mechanical dilatation is a very useful technique in the management of multiple bronchial stenoses, though perhaps only where the inflammatory process is mild or quiescent. Its use may be more limited where there is active inflammation and in such cases it is probably at best only an adjunct to systemic corticosteroid treatment.

1 Iles PB. Multiple bronchial stenoses: treatment by mechanical dilatation. Thorax 1981;36:784-6.

2 Albert RK Petty TL. Endobronchial tuberculosis progressing to bronchial stenosis. Chest 1976;70:537-9.

3 Millr A, Brown LK, Teinstein AS. Stenosis of main bronchi mimicking fixed upper airway obstruction in sarcoidosis. Chest $1985 ; 88: 244-8$.

4 Cohen MI, Gore RM, August CZ, Ossoff RH. Tracheal and bronchial stenosis associated with mediastinal adenopathy in Wegener's granulomatosis: CT findings. J Comput Assist Tomogr 1984;8:327-9.

5 Carlin BW, Harrell JH, Moser KM. The treatment of endobronchial stenosis using balloon catheter dilatation. Chest 1988;93:1148-51.

6 Vogt-Moykopf I, Toomes H, Heinrich ST. Sleeve resection of the bronchus and pulmonary artery for pulmonary lesions. Thorac Cardiovasc Surg 1983;31:193-8.

7 Caliguiri PA, Banner AS, Jensik RJ. Tuberculous mainstem bronchial stenosis treated with sleeve resection. Arch Intern Med 1984;144:1302-3.

8 Homasson JP, Renault P, Angebault M, Bonniot JP, Bell NJ. Bronchoscopic cryotherapy for airway strictures caused by tumours. Chest 1986;90:159-64.

9 Dumon JF, Reboud E, Garbe L, Aucomte F, Meric B. Treatment of tracheobronchial lesions by laser photoresection. Chest 1982;81:278-84.

10 Westaby S, Jackson JW, Pearson FG. A bifurcated silicone rubber stent for relief of tracheobronchial obstruction $J$ Thorac Cardiovasc Surg 1982;83:414-7. 